\title{
Lipogranulomatosis Subcutanea (Rothmann-Makai)
}

\author{
Wollina $\mathbf{U}^{1 *}$, Gaber $\mathbf{B}^{1}$, Schönlebe $\mathrm{J}^{2}$ \\ ${ }^{1}$ Department of Dermatology and Allergology \\ ${ }^{2}$ Institute of Pathology “Georg Schmorl", Academic Teaching Hospital Dresden-Friedrichstadt, Städtisches Klinikum, Dresden
}

Received: April 17, 2016; Accepted: April 24, 2016; Published: April 30, 2016

*Corresponding author: Prof. Dr. U. Wollina, Department of Dermatology and Allergology, Academic Teaching Hospital Dresden-Friedrichstadt, Friedrichstrasse 41, 01067 Dresden, Germany.E-mail: wollina-uw@khdf.de

\begin{abstract}
Lipogranulomatosis subcutaneous (Rothmann-Makai) is a rare localized non-infectious panniculitis of unknown etiology. We report on a 70-year-old female patient, who developed several livid subcutaneous nodules. Under the diagnosis of abscess formation a surgical incision was performed in an outwards clinic. This resulted in a suppurating lesion. Later the patient was referred to our department since antibiosis was not helpful. We took a deep biopsy. Histologic investigation demonstrated a predominant epitheloid-cell granulomatous panniculitis. The combination of clinical findings, absence of systemic symptoms and histology confirmed the diagnosis of lipogranulomatosis subcutanea. The disease is an important differential diagnosis to infectious panniculitis.
\end{abstract}

Keywords: Panniculitis; Lipogranulomatosis subcutanea; Granulomatous disorders; Treatment

\section{Case Report}

A 70-year-old female patient presented with a 10 week history of subcutaneous nodules on trunk and extremities. She had no systemic symptoms, no pain, fever or malaise. She reported that several nodules were incised (breast and arm) by a surgeon. She was treated orally with cefuroxim $500 \mathrm{mg}$ twice daily and metronidazol $400 \mathrm{mg}$ twice daily for five days without any improvement. In the last five months the patient had lost 11 $\mathrm{kg}$ body weight due to diet.

Her medical history was positive for arterial hypertension, nephrolithiasis, and coxarthrosis. About 25 years ago her uterus was removed because of cervical spotting.

On examination we observed multiple painless subcutaneous nodules on her back, right breast, left arm and shoulder and left thigh. These nodules were initially skin-colored, later bluish with some telangiectasias and skin atrophy (Figure1).

\section{Histology}

We took two biopsies from the shoulder and the back. Tissue was stained with hematoxylinin-eosin, periodic acid Schiff's reaction, pan-cytokeratin, and CD68. In both biopsies a dominant epitheloid cell, granulomatous panniculitis was described. The lesions were partially necrotic and absceding. There was no hint for actinomycosis (Figure 2).

\section{Laboratory investigation}

Antinuclear antibodies 1:80; Borrelia-IgM-westernblot negative. Angiotensin-converting enzyme decreased with 5.8 $\mathrm{U} / \mathrm{l}$ (normal range: 20-70 U/l). Alpha -1-antitrypsin and syphilis serology normal or negative.

Microbiological swabs were taken from the right breast wound and the right upper arm. Bacterial cultures remained sterile. No yeasts were detected.

\section{Imaging techniques}

Computerized tomography of the trunk was unremarkable.

\section{Treatment and course}

The persistent wounds after incisions were treated topically by sore flushing and framycetin/ lidocaine/ trypsin cones (Leukase N, Merck).

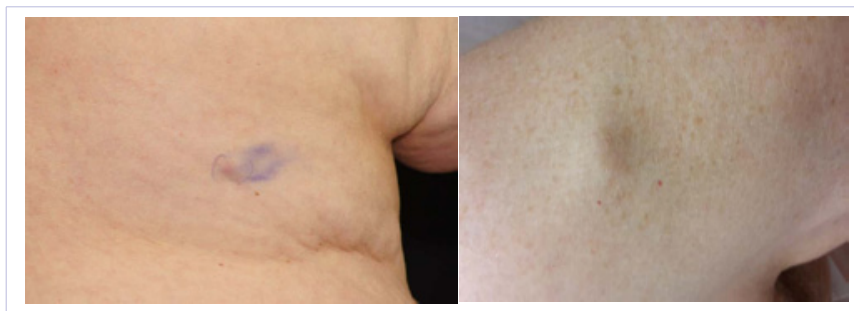

Figure 1: Presentation of Lipogranulomatisis subcutanea. Left side: Bluish colored older lesion. Right side: Earlier slightly erythematous nodule..

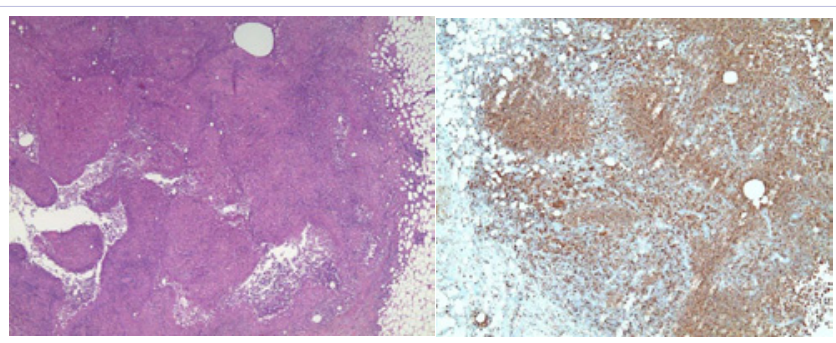

Figure 2: Histology of lipogranulomatosis subcutanea. Left side: Hematoxylinin-eosin stain (x2). Right side: Immunoperoxidase stain for CD68 (x2). 
Oral treatment with non-steroidal ibuprofen, short course of prednisolone $(80 \mathrm{mg} / \mathrm{d})$ tapered down, and pantoprazole was initiated with rapid improvement.

\section{Discussion}

Lipogranulomatosis subcutanea (Rothmann-Makai) is a rare idiopathic chronic panniculitis without systemic symptoms. There is a broad range of differential diagnoses such as erythema induratum Bazin, gummata, nodular vasculitis, lipoma, panniculitis nodularis nonsuppurativa febrilis et recividans, erythema nodosum, or abscess formation. The disease can persist for months to years. The disease has been considered an afebrile variant of panniculitis nodularis nonsuppurativa febrilis et recidivans [1] or a subtype of Weber-Christian disease withour internal manifestations [2]. Due to its rareness there is no standardized treatment. Oral corticosteroids, tetracylines and clofazimine have been used in individual patients with success $[2,3]$.

\section{References}

1. Undeutsch W, Berger HE. Lipogranulomatosis Rothmann-Makaieigenständiges Krankheitsbild oder polyätiologisches Syndrom? Hautarzt. 1996;21(5):221-225.

2. Wollina U, Karte K, Geyer A, Stuhlert A, Bocker T. Clofazimine in inflammatory facial dermatosis--granuloma faciale and lipogranulomatosis subcutanea (Rothmann-Makai). Acta Derm Venereol. 1996;76(1):77-79.

3. Asano Y, Idezuki T, Igarashi A. A case of Rothmann-Makai panniculitis successfully treated with tetracycline. Clin Exp Dermatol. 2006;31(3):365-367. 